\title{
New trends in dentistry: plant extracts against Enterococcus faecalis. The efficacy compared to chlorhexidine
}

\begin{abstract}
Adriana Lígia de Castilho(a) Cintia Helena Coury Saraceni(a) Ingrit Elida Collantes Díaz ${ }^{(\mathbf{b})}$ Mateus Luís Barradas Paciencia(b) Ivana Barbosa Suffredini ${ }^{(b)}$
\end{abstract}

(a) Graduate Program in Dentistry, Univ Paulista - UNIP, São Paulo, SP, Brazil.

(b) Center for Research in Biodiversity, Univ Paulista - UNIP, São Paulo, SP, Brazil.

Declaration of Interests: The authors certify that they have no commercial or associative interest that represents a conflict of interest in connection with the manuscript.

Corresponding author Ivana Barbosa Suffredini

E-mail: ibsuffredini@yahoo.com.br

Submitted: Aug 28, 2012

Accepted for publication: Jan 07, 2013

Last revision: Jan 17, 2013

\begin{abstract}
Enterococcus faecalis is an important pathogen associated with endodontic diseases, and its elimination and control are of paramount importance, as it represents one of the major causes of failure in the treatment of endodontic disease. Twenty-five plant extracts obtained from Brazilian forests were found to be effective against planktonic $E$. faecalis and were subjected to two traditional antibacterial assays, the microdilution broth assay (MDBA) and the disk diffusion assay (DDA), using chlorhexidine (CHX) as a control. Seven out of 25 extracts showed significant antibacterial activity and were tested in a biofilm assay, and three of these extracts were subjected to chemical fractionation. Residues were tested for their antibacterial activity, and the first chemical findings were described based on thin layer chromatography (TLC). Extracts obtained from Ipomoea alba, Symphonia globulifera and Moronobea coccinea showed significant bactericidal activity in the MDBA. The same I. alba and S. globulifera extracts, as well as the extract obtained from Connarus ruber var. ruber, showed significant activity in the DDA. $\mathrm{RH}_{2} \mathrm{O}$ obtained from Psidium densicomum and Stryphnodendron pulcherrimum showed better antibacterial activity compared to the respective crude extracts and CHX. TLC analysis showed that phenolic compounds and triterpenes represent the first findings of chemical groups that may occur in all species. The results of the present study include the discovery of six active extracts against planktonic E. faecalis and support further testing via assays involving biofilm formation, as well as the determination of the compounds' chemical profiles, as their activity was significantly better than that observed for CHX.
\end{abstract}

Descriptors: Enterococcus faecalis; Anti-Bacterial Agents; Amazonian Ecosystem.

\section{Introduction}

Enterococcus faecalis is one of the main nosocomial pathogens ${ }^{1}$ that can show resistance to a wide range of antimicrobial agents. In the oral cavity, E. faecalis is often found in caries and lesions associated with periodontal diseases. ${ }^{2}$ E. faecalis is also particularly prevalent in endodontic infections, ${ }^{3}$ in which the pulp may become infected via dentinal tubules, carious lesions, or periodontal disease. Studies have shown that E. faecalis contributes to the failure of endodontic therapy. The suppres- 
sion and control of E. faecalis in dental procedures are paramount in limiting the invasion of bacteria into dentinal tubules ${ }^{4}$ and in abolishing the establishment of any relationship with other bacteria, as in biofilms, the environment and virulence factors. ${ }^{5}$

Chlorhexidine gluconate (CHX) is widely used in periodontal and endodontal protocols, and it is found in mouth rinses that are frequently used in the treatment and prevention of caries. As E. faecalis is a facultative anaerobic microorganism, its control is of extreme importance because it can be found in the recurrent failure of endodontic treatment since it exhibits increased virulence in some pathological conditions. For this reason, it has become increasingly necessary to find new tools to assist in the fight against E. faecalis.

Systematic studies with plant extracts, ${ }^{6,7}$ fungi and animals have shown that it is possible to find compounds with pharmaceutical potential, such as penicillin, erythromycin, and tetracycline. Therefore, to discover novel compounds, over 2,000 plant extracts were tested against several microorganisms, such as Enterococcus faecalis. ${ }^{8,9}$

Based on these results, the present study aimed to determine the antibacterial activity of 25 plant extracts and their residues against E. faecalis and determine the chemical profile of the active extracts and residues, using thin layer chromatography.

\section{Methodology}

\section{Plant collection, and extraction and preparation of standard compounds}

Plants collected (permit issued by IBAMA/MMA and by CGen/MMA) in the Amazon rain forest and Atlantic forest were identified, and voucher specimens were deposited at UNIP Herbarium, São Paulo, Brazil. Organic and aqueous extracts were obtained by $24-\mathrm{h}$ maceration with dichloromethane: methanol (1:1), followed by 24-h maceration with distilled water (Millipore ${ }^{\circledR}$, Bedford, USA). ${ }^{10}$

The 25 extracts were diluted to $250,200,150$, $100,50,25,12.5,10.0,7.5,5.0,2.5$, and $1.3 \mathrm{mg} /$ $\mathrm{mL}$ (the final test concentration in the microdilution broth assay is 20 times more diluted). Standard chlorhexidine digluconate (CHX) concentrations of $0.12 \%, 1 \%$ and $2 \%$ were obtained from a $20 \%$ so- lution of formulated CHX (Fórmula \& Ação, São Paulo, Brazil).

\section{Disk diffusion assay and determination of the growth inhibition zone diameter}

The disk diffusion assay (DDA) was performed according to the standards of the Clinical and Laboratory Standards Institute (CLSI, $8^{\text {th }}$ edition), in sterile conditions. A 0.5 MacFarland saline suspension was prepared from fresh bacterial colonies. The assay was performed with Müeller-Hinton agar (MHA) prepared in Petri dishes. Swabs were used to seed bacteria onto the medium's surface. Six paper disks measuring $6 \mathrm{~mm}$ in diameter were distributed over the surface of the inoculated medium. Ten $\mu \mathrm{L}$ of drug were added to each disk, in triplicate. Dishes were incubated at $36^{\circ} \mathrm{C}$ for $24 \mathrm{~h}$. The diameter of the growth inhibition zones was measured horizontally and vertically with a caliper rule.

\section{Microdilution broth assay and determination of the minimal inhibitory and bactericidal concentrations}

Extracts were tested using the microdilution broth assay (MDBA), in sterile conditions, according to CLSI standards ( $8^{\text {th }}$ edition). The assay was adapted for high-throughput conditions ${ }^{8}$ using MüellerHinton broth (MHB) medium (Oxoid, London, England) in 96-well microplates. Inocula were adjusted to $1 \times 10^{8}$ colony-forming units per $\mathrm{mL}(\mathrm{CFU} / \mathrm{mL})$ with fresh colonies of E. faecalis ATCC ${ }^{\circledast} 29212^{\mathrm{TM}}$ grown on sterilized MHA (Oxoid, London, England). Bacterial suspensions of different concentrations were prepared in $\mathrm{MHB}$ from the $1 \times 10^{8} \mathrm{CFU} /$ $\mathrm{mL}$ suspension. A $190-\mu \mathrm{L}$ aliquot of the bacterial suspension was dispensed into the wells, and a 10$\mu \mathrm{L}$ aliquot of extract, residue or standard solution was then added to the wells. Microplates were incubated at $36^{\circ} \mathrm{C}$ for $24 \mathrm{~h}$. The inhibition of bacterial growth was visually assessed, and bacterial suspensions from all test wells were subcultured in sterile MHA to evaluate the effectiveness of treatments.

Using a similar procedure, the minimal inhibitory concentrations (MICs) and minimal bactericidal concentrations (MBCs) against E. faecalis were obtained for the 25 plant extracts. 


\section{Activity on planktonic biofilm formation}

Extracts 321, 352, 1257, 1493, 1525, 1765 and 1991 were tested in a planktonic biofilm assay ${ }^{11}$ adapted to E. faecalis to assess their biofilm prevention potential. Briefly, $2 \mathrm{~mL}$ of $\mathrm{MH}$ broth medium enriched with 5\% saccharose (MHS) and inoculated with $1.5 \times 10^{6} \mathrm{CFU} / \mathrm{mL}$ E. faecalis was added to each well of a 24-well microplate (Costar, Tewksbury, USA). The extracts $(\mathrm{n}=3)$ were added to a final concentration of $3 \mathrm{mg} / \mathrm{mL}$, except for saline, which was used as a control. One vulcanized titanium disk $(6 \mathrm{~mm}$ diameter $\times 2 \mathrm{~mm}$ height; Conexão, Arujá, Brazil) was placed in each well as a biofilm support. Plates were kept in an incubator at $36^{\circ} \mathrm{C}$ for $20 \mathrm{~h}$. Disks were transferred to 24-well microplates containing $2 \mathrm{~mL}$ of sterile saline per well. Plates were shaken for 1 minute in an orbital shaker. Disks were transferred to 24-well microplates containing sterile MHS. Plates were incubated for $48 \mathrm{~h}$. Finally, each titanium disk was transferred in a vial containing $2 \mathrm{~mL}$ of MHS that was vortexed for 2 minutes so that $\mathrm{CFU} / \mathrm{mL}$ counts could be obtained. One-way ANOVA and Tukey's post-test were used to compare means $(\mathrm{p}<0.05)$.

\section{Liquid-liquid partition and biological assay of residues}

The 25 extracts were partitioned with chloroform $\left(\mathrm{RCHCl}_{3}\right)$, butanol $(\mathrm{RBuOH})$ and water $\left(\mathrm{RH}_{2} \mathrm{O}\right)$, resulting in 75 residues. Organic solvents were completely removed under vacuum, and the water was lyophilized to avoid any interference in the biological assays. $\mathrm{RCHCl}_{3}$ and $\mathrm{RBuOH}$ samples were re-suspended in 50\% dimethylsulfoxide (DMSO50), and all $\mathrm{RH}_{2} \mathrm{O}$ samples were diluted with Milli-Q distilled water (Millipore ${ }^{\circledR}$, Bedford, USA), to a concentration of $200 \mathrm{mg} / \mathrm{mL}$ for testing. DMSO50 did not show antibacterial activity in the present protocols, and, for that reason, it was chosen as the solvent used in the biological assays.

\section{Thin-layer chromatography}

Thin-layer chromatography (TLC) was performed with silica gel GF chromatography sheets (Merck $^{\circledR}$, New Jersey, USA), using the mobile phase systems:
- S1 - hexane and ethyl acetate (4:1) applied on chromatography sheet 1 ;

- S2 - chloroform and ethyl acetate (1:1) applied on chromatography sheet 2 ;

- S3 - chloroform, ethyl acetate and methanol $(2: 2: 1)$;

- S4 - ethyl acetate, methanol and water (100:13.5:10);

- S5 - ethyl acetate, glacial acetic acid, formic acid and water (100:11:11:26).

Detection of spots was performed with

- potassium hydroxide (A),

- Kedde reagent (B),

- Dragendorff reagent $(\mathrm{C})$,

- NP reagent $(\mathrm{D})$,

- $25 \%$ sulfuric acid solution (E) and

- $\beta$-carotene $(\mathrm{F})$.

Ultraviolet light at 254 and/or $356 \mathrm{~nm}$ (uv 254 or uv 356) was used to develop some of the chromatograms.

\section{Results}

Taxonomic information for the 25 plants included in the present study is provided elsewhere. Full taxonomic information is provided in the text only for the extracts that show antibacterial activity.

The 25 tested extracts were classified according to their antibacterial potential. Extracts were considered active if the $\mathrm{MBC}$ was $\leq 0.31 \mathrm{mg} / \mathrm{mL}$. Only three extracts were classified within this group (Figure 1) at the bacterial concentration of $1 \times 10^{7} \mathrm{CFU} /$ $\mathrm{mL}$. Eight extracts were classified as intermediately active (the MBCs ranged from 0.31 to $5.0 \mathrm{mg} / \mathrm{mL}$ ). The remaining 14 extracts were considered to be weakly active.

Figure 2 shows a comparison of the antibacterial activity of the crude extracts, their $\mathrm{RCHCl}_{3}$, $\mathrm{RBuOH}$, and $\mathrm{RH}_{2} \mathrm{O}$, and the standard solutions (CHX 0.12\%, 1\%, and 2\%). Two-way ANOVA and Bonferroni multiple comparisons tests were performed. The treatments with extracts/ residues account for $47.99 \%$ of the total variance $\left(\mathrm{F}_{[27,560]}=1030.60 ; \mathrm{p}<0.001\right)$, the fractionation accounts for $13.45 \%$ of the variance $\left(\mathrm{F}_{[3,560]}=2559.96\right.$; 

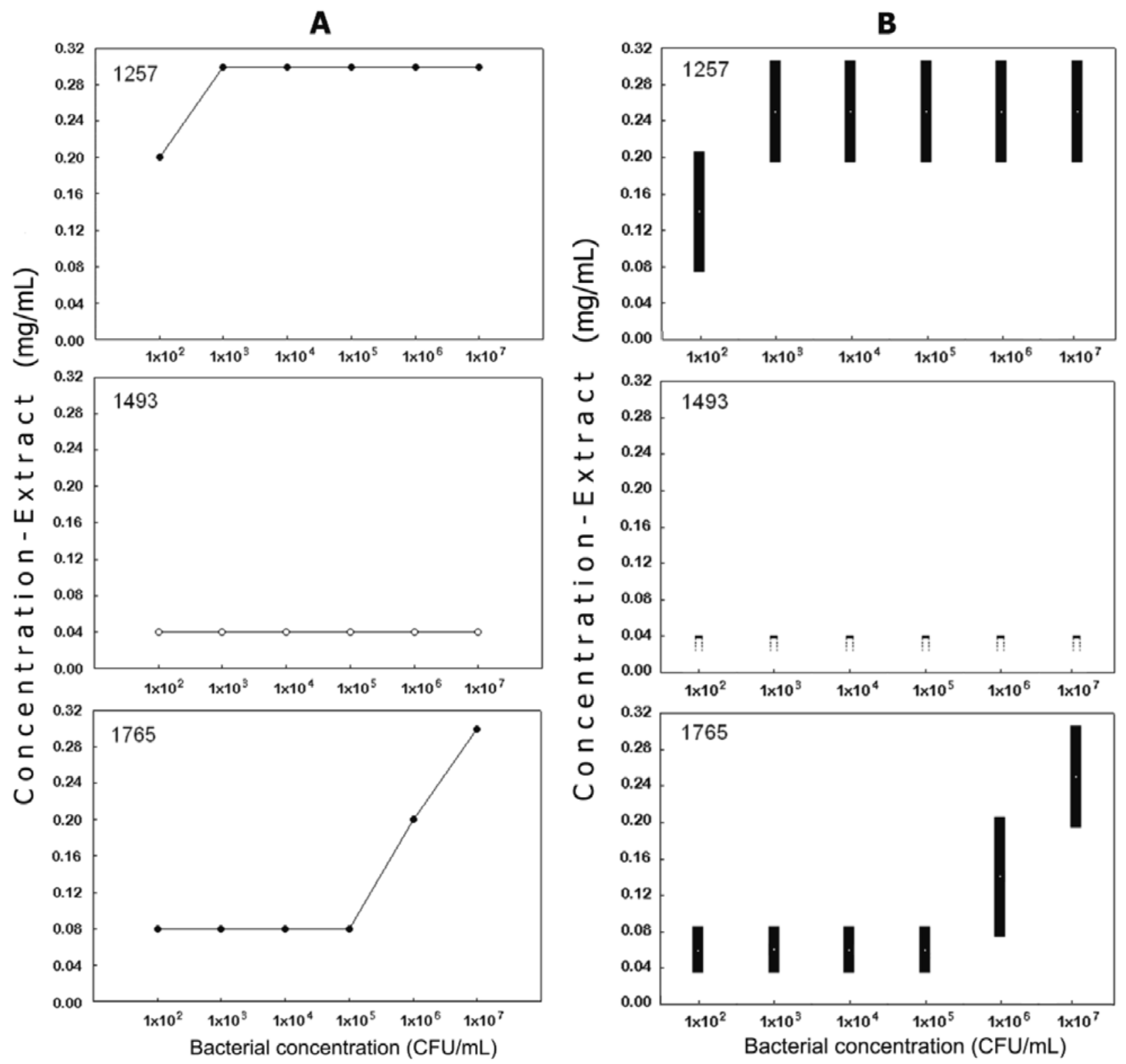

Figure 1 - A: Minimal bactericidal concentration for extracts 1257 (Symphonia globulifera, Clusiaceae), 1493 (Ipomoea alba, Convolvulaceae), and 1765 (Moronobea coccinea, Clusiaceae). B: Minimal inhibitory concentration for the same active extracts.

$\mathrm{p}<0.001$ ), and the interactions between both factors accounts for $37.60 \%$ of the total variance $\left(\mathrm{F}_{[81,560]}=269.14 ; \mathrm{p}<0.001\right)$. All parameters are considered extremely significant. Only treatments that showed significant antibacterial activity relative to the standard solutions are described, with preference to residues over extracts. $\mathrm{RBuOH}$ obtained from extracts 55, 841, 1259, 1298, 1389, 1497,1525 and 1743 was as active as CHX $0.12 \%$ ( $\mathrm{p}>0.05) \cdot \mathrm{RH}_{2} \mathrm{O}$ obtained from extract 321 was significantly active compared to all $\mathrm{CHX}$ concentrations, particularly to $1 \%$ and $2 \%$ ( $\mathrm{p}>0.05)$. $\mathrm{RBuOH}$ and $\mathrm{RH}_{2} \mathrm{O}$ obtained from extract 1257 were as active as CHX $0.12 \%(\mathrm{p}>0.05)$. RCH$\mathrm{CL}_{3}(\mathrm{p}>0.05)$ and $\mathrm{RBuOH}(\mathrm{p}<0.01)$ obtained from extract 1493 were more active than CHX $0.12 \%$. RCHCl3 obtained from extracts 1549 and 1991 was as active as CHX 0.12\%. Extracts 321, 1257, 1493, 1525, 1765 and 1991 prevented biofilm formation, as did CHX $0.12 \%$ and $\mathrm{CHX} 1 \%$ 


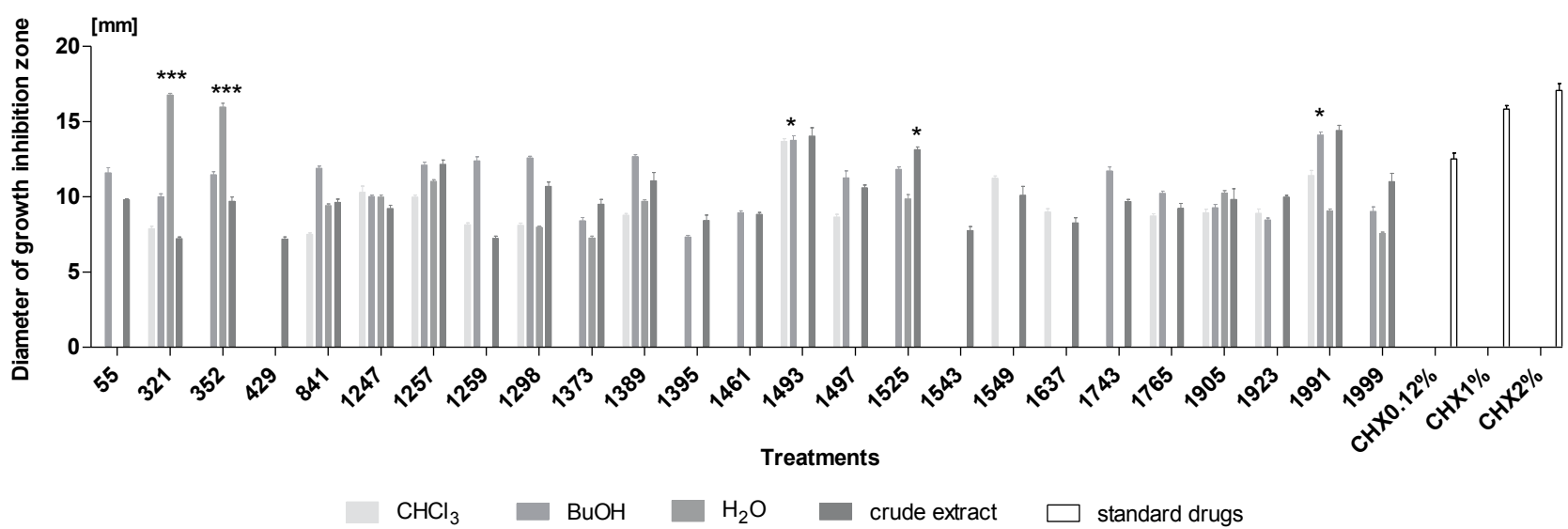

Figure 2 - Disk diffusion assay against Enterococcus faecalis ATCC 29212. Each number corresponds to the group of treatments composed by the crude extracts and their $\mathrm{RCHCl}_{3}, \mathrm{RBuOH}$ and $\mathrm{RH}_{2} \mathrm{O}$ residues. $\mathrm{CHX}=$ chlorhexidine gluconate. Analysis was performed by two-way ANOVA ( $p<0.05)$.

$\left(\mathrm{F}_{[8,26]}=184.3 ; \mathrm{p}<0.001\right)$. Extract 352 did not show significant results relative to the control groups $(\mathrm{p}>0.05)$ (Figure 3).

TLC analysis of the crude extracts that showed significant antibacterial activity (extracts 321, 352, 1493, 1525, and 1991) was performed, and the results showed that extract 321 may not have alkaloids, anthraquinone-like compounds or cardenolides; however, it may have phenolic compounds, as a weak blue fluorescence could be seen after NP and uv 356 development, as well as triterpenes or essential oils after sulfuric acid development. Additionally, extract 352 may also have phenolic compounds (yellow spots after NP and uv 356 development) and triterpenes or essential oils. Extract 1493 may have triterpenes as major compounds, as the sulfuric acid solution was able to develop the chromatogram. Extract 1525 may contain coumarins and triterpenes. Lastly, extract 1991 showed a yellow spot after development with $\mathrm{KOH}$, suggesting anthrone-like compounds, as well as 3 orange spots and 1 yellowgreen spot after development with NP and uv 356.

\section{Discussion}

E. faecalis is an important pathogen in diseases affecting the oral cavity, such as recurrent endodontic infection, that is commonly associated with treatment failure. ${ }^{3} \mathrm{CHX}$ is still the treatment compound of choice in Dentistry and is usually considered the gold standard in in house assays. None-

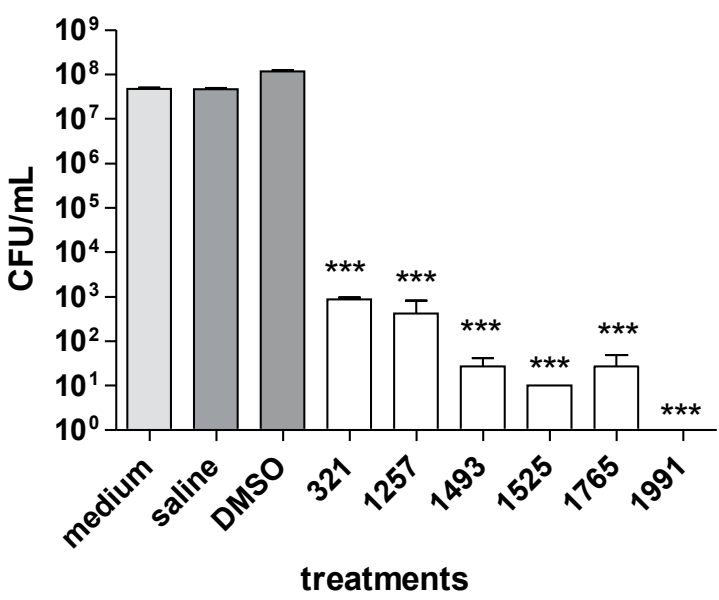

Figure 3 - Prevention on Enterococcus faecalis biofilm formation after treatment with Amazon plant extracts, compared to control without treatments. One-way ANOVA and Tukey's post-test ( $p<0.01)$.

theless, the compound has known undesirable side effects, which are often disregarded because of the compound's antimicrobial therapeutic benefit. Therefore, substances that have similar therapeutic efficacy and fewer side effects should be tracked and used in dental therapy. Natural products, such as propolis ${ }^{12}$ and other Brazilian plant extracts, ${ }^{13}$ are also being investigated for their antibacterial activity, particularly to be employed in dentistry.

Two experimental models, the DDA and the MDBA, were selected to evaluate the potential antimicrobial activity of plant extracts against E. faeca- 
lis. Both models contributed to the identification of new compounds with the potential to be used against bacteria in in house experiments. The identity of the most suitable test to be used in natural products research has been widely discussed elsewhere. ${ }^{14}$

The MDBA showed that only three out of $25 \mathrm{ex}-$ tracts $(1257,1493$ and 1765) were effective against the assayed bacteria (Figure 1). In relation to MBC, extract 1493 showed a $\mathrm{MBC} \leq 0.04 \mathrm{mg} / \mathrm{mL}$ and extract 1257 and 1765 showed MBCs $\leq 0.31 \mathrm{mg} / \mathrm{mL}$. Extract 1493 was obtained from the aerial organs of Ipomoea alba L. (Convolvulaceae), a plant that has received little study. Sweet potato is one of the species belonging to this genus. Clavine alkaloids occur in I. muricata, ${ }^{15}$ and ipobscurines occur in $I . o b$ scura. ${ }^{16}$ Other alkaloids, anthocyanins and polyphenolic compounds occur in some toxic species such as I. carnea. ${ }^{17}$ Extract 1257 was obtained from the aerial organs of Symphonia globulifera, and extract 1765 was obtained from the flowers of Moronobea coccinea; both species belong to Clusiaceae. S. globulifera showed significant antimalarial activity, which may be due to the presence of polycyclic polyprenylated acylphoroglucinols and oxidized derivatives, ${ }^{18}$ which were also isolated from M. coccinea. Xanthone derivatives and flavonoids have shown antimicrobial, ${ }^{19}$ anti-Leishmania, ${ }^{20}$ antiprotozoal and cytotoxic ${ }^{21}$ activities. Antiplasmoidal benzophenones were isolated from the trunk latex of $M$. coccinea. ${ }^{22}$ Three extracts were fractionated, and the corresponding residues were analyzed by their antioxidant activity. The results indicated that the residues showed no antioxidant activity except for the $\mathrm{RBuOH}$ from extract 1257 .

$\mathrm{RBuOH}$ from extract 1257 expressed antioxidant activity, which may be related to the presence of phenolic compounds such as flavonoids and their derivatives, isoflavonoids, chalcones, catechins, free phenolic acids, lignans, curcumin and its derivatives, and/or to the presence of specific alkaloids and related compounds. Such compounds may be involved in both antibacterial and antioxidant activity, although there is no relationship between antioxidative processes and antibacterial agents.

The DDA showed a different group of active extracts: 1493, 1525 and 1991. Extract 1493 was previously discussed. Extract 1525 was obtained from the stem of Connarus ruber var. ruber (Connaraceae). Anti-inflammatory and analgesic activities were reported for a different species belonging to Connaraceae. ${ }^{23}$ Extract 1991 was obtained from the aerial organs of $S$. globulifera, which was previously discussed but collected at a different time. The first TLC findings described here for the active extracts are in agreement with chemical findings in the literature and will support our future work on the chemistry of each extract.

After extracts 321 and 352 were fractionated, a significant improvement in the antibacterial activity was observed in their $\mathrm{RH}_{2} \mathrm{O}$. For this reason, both extracts will be studied in the near future. Extract 321, obtained from the leaves of Psidium densicomum (Myrtaceae), belongs to a group of plants (guajava family) known to contain terpenes, triterpenoids and flavonoids. ${ }^{24}$ Extract 352 was obtained from the aerial parts of Stryphnodendron pulcherrimum (Fabaceae), a species taxonomically related to a medicinal plant known in Brazil as barbatimao. This plant was already studied against oral pathogens and is known to contain tannins as the main class of chemical compounds. Although extract 352 did not show any activity against biofilm formation, extracts 321, 1257, 1493, 1525, 1765 and 1991 significantly prevented biofilm formation and show promise for the study of biofilm prevention strategies using chemical products obtained from nature.

\section{Conclusions}

Nature is a potential source of new chemicals for use in dentistry. In the present work, seven plant extracts obtained from species native to the Amazon rain forest showed significant in vitro activity against E. faecalis, and six out of the seven extracts proved to be potent agents in preventing biofilm formation.

\section{Acknowledgments}

The authors thank CAPES/PROSUP for the research grant to ADL, Fapesp (grants \# 99/05904-6 and 08/58706-8) and UNIP for support. 


\section{References}

1. Horner R, Liscano MG, Maraschin MM, Salla A, Meneghetti B, Dal Forno NLF, et al. Suscetibilidade antimicrobiana entre amostras de Enterococcus isoladas no Hospital Universitário de Santa Maria. J Bras Patol Med Lab. 2005 Dez;41(6):391-5.

2. Souto R, Andrade AFB, Uzeda M, Colombo APV. Prevalence of "non-oral" pathogenic bacteria in subgingival biofilm of subjects with chronic periodontitis. Braz J Microbiol. 2006 Jul;37(3):208-15.

3. Hancock HH 3rd, Sigurdsson A, Trope M, Moiseiwitsch J. Bacteria isolated after unsuccessful endodontic treatment in a North American population. Oral Surg Oral Med Oral Pathol Oral Radiol Endod. 2001 May;91(5):579-86.

4. Love MR. Enterococcus faecalis - a mechanism for its role in endodontic failure. Int Endod J. 2001 Jul;34(5):399-405.

5. Kayaoglu G, Orstavik D. Virulence factors of Enterococcus faecalis: relationship to endodontic disease. Crit Rev Oral Biol Med. 2004 Sep;15(5):308-20.

6. Alviano WS, Alviano DS, Diniz CG, Antoniolli AR, Alviano CS, Farias LM, et al. In vitro antioxidant potential of medicinal plant extracts and their activities against oral bacteria based on Brazilian folk medicine. Arch Oral Biol. 2008 Jun;53(6):545-52.

7. Bakri IM, Douglas CW. Inhibitory effect of garlic extract on oral bacteria. Arch Oral Biol. 2005 Jul;50(7):645-51.

8. Suffredini IB, Sader HS, Gonçalves AG, Reis AO, Gales AC, Varella AD, et al. Screening of antibacterial active extracts obtained from plants native to Brazilian Amazon rain forest and Atlantic forest. Braz J Med Biol Res. 2004 Mar;37(3):37984.

9. Suffredini IB, Paciencia MLB, Varella AD, Younes RN. Antibacterial activity of Brazilian Amazon plant extracts. Braz J Infect Dis. 2006 Dec;10(6):400-2.

10. Younes RN, Varella AD, Suffredini IB. Discovery of new antitumoral and antibacterial drugs from Brazilian plant extracts using high throughput screening. Clinics. 2007 Nov;62(6):763-8.

11. Silva MP, Chibebe Junior J, Jorjão AL, Machado AKS, Oliveira $L D$, Junqueira JC, et al. Influence of artificial saliva in biofilm formation of Candida albicans in vitro. Braz Oral Res. 2012 Jan-Feb;26(1):24-8.

12. Kayaoglu G, Ömürlü H, Akca G, Gürel M, Gençay Ö, Sorkun $\mathrm{k}$, et al. Antibacterial activity of propolis versus conventional endodontic disinfectants against Enterococcus faecalis in infected dentinal tubules. J Endod. 2011 Mar;37(3):376-81.

13. Barrella GE, Suffredini IB, Ribeiro FV, Cirano FR, Pimentel SP. Evaluation of the effect of an organic extract obtained from Ipomoea alba L. on experimental periodontitis in rats. Braz Oral Res. 2012 Mar-Apr;26(2):158-64.
14. Cowan MM. Plant products as antimicrobial agents. Clin Microbiol Rev. 1999 Oct;12(4):564-82.

15. Maurya A, Srivastava SK. Large-scale separation of clavine alkaloids from Ipomoea muricata by $\mathrm{pH}$-zone-refining centrifugal partition chromatography. J Chromatogr B Analyt Technol Biomed Life Sci. 2009 Jun;877(18-19):1732-6.

16. Jenett-Siems K, Weigl R, Kaloga M, Schulz J, Eich E. Ipobscurines $\mathrm{C}$ and $\mathrm{D}$ : macrolactam-type indole alkaloids from the seeds of Ipomoea obscura. Phytochemistry. 2003 Apr;62(8):1257-63.

17. Haraguchi M, Gorniak SL, Ikeda K, Minami Y, Kato A, Watson AA, et al. Alkaloidal components in the poisonous plant, Ipomoea carnea (Convolvulaceae). J Agric Food Chem. 2003 Aug;51(17):4995-5000.

18. Marti G, Eparvier V, Moretti C, Prado S, Grellier P, Hue N, et al. Antiplasmodial benzophenone derivatives from the root barks of Symphonia globulifera (Clusiaceae). Phytochemistry. 2010 Jun;71(8-9):964-74.

19. Mkounga P, Fomum ZT, Meyer M, Bodo B, Nkengfack AE. Globulixanthone $\mathrm{F}$, a new polyoxygenated xanthone with an isoprenoid group and two antimicrobial biflavonoids from the stem bark of Symphonia globulifera. Nat Prod Commun. 2009 Jun;4(6):803-8.

20. Lenta BN, Vonthron-Sénécheau C, Weniger B, Devkota KP, Ngoupayo J, Kaiser M, et al. Leishmanicidal and cholinesterase inhibiting activities of phenolic compounds from Allanblackia monticola and Symphonia globulifera. Molecules. 2007 Aug;12(8):1548-57.

21. Ndjakou Lenta B, Vonthron-Sénécheau C, Fongang Soh R, Tantangmo F, Ngouela S, Kaiser M, et al. In vitro antiprotozoal activities and cytotoxicity of some selected Cameroonian medicinal plants. J Ethnopharmacol. 2007 Jan;111(1):8-12.

22. Marti G, Eparvier V, Moretti C, Susplugas S, Prado S, Grellier $\mathrm{P}$, et al. Antiplasmodial benzophenones from the trunk latex of Moronobea coccinea (Clusiaceae). Phytochemistry. 2009 Jan;70(1):75-85.

23. Ishola IO, Akindele AJ, Adeyemi OO. Analgesic and antiinflammatory activities of Cnestis ferruginea Vahl ex DC (Connaraceae) methanolic root extract. J Ethnopharmacol. 2011 Jan;135(1):55-62.

24. Ho R, Violette A, Cressend D, Raharivelomanana P, Corrupt PA, Hostettmann K. Antioxidant potential and radicalscavenging effects of flavonoids from the leaves of Psidium cattleianum grown in French Polynesia. Nat Prod Res. 2012 Mar;26(3):274-7. 